University of Montana

ScholarWorks at University of Montana

Integrative Physiology and Athletic Training

Faculty Publications

Integrative Physiology and Athletic Training

$2-2003$

\title{
Estradiol Effects on the Growth Hormone/Insulin-Like Growth \\ Factor-1 Axis in Amenorrheic Athletes
}

Debra L. Waters

Richard I. Dorin

Clifford R. Qualls

Brent Ruby

University of Montana - Missoula, brent.ruby@umontana.edu

Richard N. Baumgartner

See next page for additional authors

Follow this and additional works at: https://scholarworks.umt.edu/hhp_pubs

Part of the Medicine and Health Sciences Commons

Let us know how access to this document benefits you.

\section{Recommended Citation}

Waters, Debra L.; Dorin, Richard I.; Qualls, Clifford R.; Ruby, Brent; Baumgartner, Richard N.; and Robergs, Robert A., "Estradiol Effects on the Growth Hormone/Insulin-Like Growth Factor-1 Axis in Amenorrheic Athletes" (2003). Integrative Physiology and Athletic Training Faculty Publications. 6.

https://scholarworks.umt.edu/hhp_pubs/6

This Article is brought to you for free and open access by the Integrative Physiology and Athletic Training at ScholarWorks at University of Montana. It has been accepted for inclusion in Integrative Physiology and Athletic Training Faculty Publications by an authorized administrator of ScholarWorks at University of Montana. For more information, please contact scholarworks@mso.umt.edu. 
Authors

Debra L. Waters, Richard I. Dorin, Clifford R. Qualls, Brent Ruby, Richard N. Baumgartner, and Robert A. Robergs 


\title{
Estradiol Effects on the Growth Hormone/Insulin-Like Growth Factor-1 Axis in Amenorrheic Athletes
}

\author{
Debra L. Waters, Richard I. Dorin, Clifford R. Qualls, Brent C. Ruby, \\ Richard N. Baumgartner, and Robert A. Robergs
}

\section{Catalog Data}

Waters, D.L., Dorin, R.I., Qualls, C.R., Ruby, B.C., Baumgartner, R.N., and Robergs, R.A. (2003). Estradiol effects on the growth hormone/insulin-like growth factor-1 axis in amenorrheic athletes. Can. J. Appl. Physiol. 28(1): 64-78. (2003 Canadian Society for Exercise Physiology.

Key words: transdermal estradiol, insulin-like growth factor binding protein-3, insulin-like growth factor binding protein-1, free fatty acids

Mots clés: aestradiol transdermique, protéine de liaison des facteurs de type insuline-3, protéine de liaison des facteurs de type insuline-1, acides gras libres

\begin{abstract}
Résumé
Disruption of the growth hormone/insulin-like growth factor-1 (GH/IGF-1) axis has been reported and studied in menopause, hypothalamic amenorrhea, and anorexia nervosa, but not in weight-stable amenorrheic athletes. We investigated the effects of short-term transdermal estradiol on basal and exercise-stimulated serum $G H, I G F-1$, and associated binding proteins (IGFBP-1 and IGFBP-3) in seven weight-stable female amenorrheic athletes with percentage body fats greater that $12 \%$. Each subject received a $72 \mathrm{~h}$ placebo patch followed by $144 \mathrm{~h}$ of transdermal estradiol. Serum samples for GH, IGF-1, IGFBP-1,

D.L. Waters and R.N. Baumgartner are with the School of Medicine, Department of Internal Medicine, University of New Mexico, Albuquerque, NM; R.I. Dorin is with the Department of Internal Medicine, New Mexico Veterans Affairs Health Care System, Albuquerque, NM; C.R. Qualls is with the General Clinical Research Center- Biostatistics, University of New Mexico, Albuquerque, NM; B.C. Ruby is with the Department of Health and Human Performance, University of Montana, Missoula, MT; and R.A. Robergs is with the Center for Exercise and Applied Human Physiology, University of New Mexico, Albuquerque, NM.
\end{abstract}


and IGFBP-3 were obtained at baseline (t1), $72 \mathrm{hr}(\mathrm{t} 2), 144 \mathrm{hr}(\mathrm{t} 3)$, and during three 90 minute trials of aerobic exercise. Basal, and exercise GH, IGF-1, and IGFBP-1 were not different between trials. Baseline IGFBP-3 decreased from $t 1$ to $t 2(\mathrm{p}=0.04)$ and serum free fatty acids increased from $t \mathrm{l}$ to $t 2$, and $t 1$ to $t 3$ ( $\mathrm{p}=0.04$, and 0.02 respectively). These findings differ from postmenopausal women, and women having weightloss-associated amenorrhea, suggesting that estrogen, exercise, and nutritional deficiencies may have independent effects on the GH/IGF-I axis.

Le dérèglement de l'axe hormone de croissance facteur de croissance de type insuline-1 (GH/IGF-1) a été observé et étudié chez les femmes ménopausées, les femmes souffrant d'aménorrhée hypothalamique et d'anorexie mentale, mais non chez les athlètes en aménorrhée et de masse corporelle stable. Nous avons étudié les effets à court terme de l'ostradiol transdermique sur les niveaux sériques de base et à l'effort de GH, IGF-1, et des protéines de liaison associées (IGFBP-1 et IGFBP-3) chez sept athlètes féminines en aménorrhée, de masse corporelle stable et dont le pourcentage de gras est plus de $12 \%$. Tous les sujets se sont appliqués un timbre témoin durant 72 h puis un timbre d'cestradiol durant 144 h. Les concentrations sériques de GH, IGF-1, IGFBP-1 et IGFBP-3 ont été mesurées à $t 1$ (base), $t 2(72 h)$ et $t 3(144 h)$ et au cours de trois épreuves aérobies d'une durée de $90 \mathrm{~min}$. Les concentrations sériques de GH, IGF-1, IGFBP-1 furent les mêmes à l'effort qu'au repos. Le niveau de base de IGFBP-3 a diminué de $t 1$ à $t 2(p=0,04)$ et le niveau sérique des acides gras libres a augmenté de $t 1$ à $t 2$ et de $t 1$ à $t 3(p=0,04$, et 0,02 , respectivement). Ces observations diffèrent de celles observées chez les femmes ménopausées et chez les femmes en aménorrhée ayant perdu du poids, ce qui signifie probablement que les restrogènes, l'exercice et les carences alimentaires ont des effets indépendants sur l'axe GH/IGF-1.

\section{Introduction}

Various biological conditions such as aging, starvation, sex steroid deficiencies, and obesity, appear to affect the secretion of growth hormone (GH), insulin-like growth factor-1 (IGF-1) and the associated binding proteins. Insulin-like growth factor (IGF) binding proteins serve as carriers of IGF in the circulation, prolong the half-life of the IGF's, and act as regulators of the biological actions by regulating the availability of IGF's to their cell surface receptors (Koistinen et al., 1996). Estrogen is one important mediator of $\mathrm{GH}$ secretion, and the effect of endogenous, oral and transdermal estrogen on the GH/IGF-1 axis has been investigated during aging, menopause, and weightloss-associated amenorrhea (Bellantoni et al., 1996; Cano et al., 1999; Genazzani et al., 1998).

In human studies designed to assess the effects of estrogen on the GH/IGF-1 axis, two variables appear to be critical; namely the etiology of the estrogen deficiency, and the route of estrogen administration (oral vs. transdermal). The biological effects of estrogen replacement have been primarily studied in post-menopausal women or in younger women experiencing hypothalamic amenorrhea secondary to weight loss or anorexia nervosa (Bellantoni et al., 1996; Genazzani et al., 1993; O'Sullivan et al., 1998). Weightloss-associated hypothalamic amenorrhea is characterized by decreased percentage of body fat, nutritional deficiencies, and low insulin and leptin concentrations all of which may independently influence GH and IGF-1 concentrations (De Cree, 1998; Laughlin et al., 1998; Yen and 
Laughlin, 1996). An alternative model of amenorrhea is the syndrome of athletic amenorrhea. Although women with athletic and weightloss-associated hypothalamic amenorrhea share several features, they differ importantly in several parameters (Laughlin et al., 1998; Yen, 1993; Yen and Laughlin, 1996). For example, women with a severe form of weight loss (anorexia nervosa) demonstrate hypercholesterolemia, decreased 3,5,3'-Triiodothyronine $\left(T_{3}\right)$ and reverse $T_{3}$ all which coexist with psychological impairments (De Cree, 1998). Conversely, amenorrheic athletes without weight loss or eating disorders do not exhibit these metabolic anomalies, but do demonstrate alterations in the GH/IGF-1 axis (Waters et al., 2001).

To our knowledge, the effect of short-term transdermal estradiol supplementation on the GH/IGF-1 axis has not been investigated in weight-stable amenorrheic athletes. Thus, the present study is designed to determine if short-term, transdermal estradiol replacement alters baseline and exercise stimulated serum GH and IGFBP-1 concentrations, resting measures of serum IGF-1 and associated binding proteins or other metabolic parameters in young adult women with amenorrhea and estrogen deficiency due to athletic training.

\section{Materials and Methods}

\section{SUBJECTS}

Seven female athletes diagnosed with hypoestrogenemic athletic amenorrhea signed informed consent, which was approved by the University of New Mexico Human Research Review Committee.

A University of New Mexico outpatient General Clinical Research Center (GCRC) appointment was scheduled and each subject completed a medical health history, exercise habits questionnaire and eating attitudes test (Garner et al., 1982). Nutritional habits were further discussed with a registered dietician from the GCRC in a personal interview. Following this preliminary screening, subjects were scheduled for a complete physical examination, which included basal blood sampling.

The classification of athletic amenorrhea was based on the features brought forth by Loucks and Horvath (1985), and was defined as the absence of menstruation for no less than three consecutive months prior to testing with sustained hypoestrogenemia during a 3-week baseline testing period (3-week mean serum estrogen level less than $75 \mathrm{pmol} \cdot \mathrm{L}^{-1}$ ). Presence of chronic anovulation during the menstrual cycle was confirmed by basal progesterone $\left(\mathrm{P}_{4}\right)$ levels less than $12 \mathrm{nmol}$ $\cdot \mathrm{L}^{-1}$, and a lack in the biphasic elevation in basal body temperature over 30 days.

All subjects were currently involved in a regular training regimen and described their average daily exercise routine as approximately 2 hours of aerobic exercise per day (Table 1). The seven females in this study were comprised of four recreational runners, one recreational triathlete, one competitive runner/cyclist, and one collegiate heptathlete. Subjects were in good health and were required to have body fat greater than $12 \%$, but less than $23 \%$ (measured by Dual Energy Xray Absorptiometry), and a measured $\mathrm{VO}_{2}$ max exceeding $40 \mathrm{ml} \cdot \mathrm{kg}^{-1} \cdot \mathrm{min}^{-1}$.

Although seven amenorrheic athletes completed the study, only partial data was available for one subject due to sampling difficulties. Sample sizes per outcome measure are presented in the tables and figures. 
Table 1 Physical Characteristics and Demographic Data of Baseline

\begin{tabular}{|c|c|c|}
\hline Variable & $\begin{array}{l}\text { Amenorrheics } \\
\quad(n=7)\end{array}$ & $\begin{array}{l}\text { Eumenorrheics } \\
\qquad(n=5)\end{array}$ \\
\hline Age (years) & $26.8 \pm 5$ & $27.8 \pm 4$ \\
\hline Age at menarche (years) & $12.9 \pm 1$ & $13.0 \pm 2$ \\
\hline Duration of amenorrhea (months) & $9.9 \pm 6$ & N/A \\
\hline Body weight (kg) & $57.4 \pm 7$ & $58.3 \pm 5$ \\
\hline Body fat (\%) & $15.0 \pm 3$ & $24.4 \pm 4^{*}$ \\
\hline Years training & $6.9 \pm 4$ & $10.4 \pm 5^{*}$ \\
\hline Exercise (average $\min \cdot$ day $^{-1}$ ) & $132.9 \pm 71$ & $120.7 \pm 40$ \\
\hline $\mathrm{VO}_{2 \max }\left(\mathrm{ml} \cdot \mathrm{kg}^{-1} \cdot \mathrm{min}^{-1}\right)$ & $47.0 \pm 7$ & $52.1 \pm 2^{*}$ \\
\hline Estradiol $\left(\mathbf{p m} \cdot \mathbf{L}^{-1}\right)$ & $140.9 \pm 34.5$ & $284.1 \pm 59 . *$ \\
\hline P4 $\mathrm{nmol} \cdot \mathrm{L}^{-1}$ (single sample) & $0.95 \pm 0.3$ & $17.2 \pm 1.9 *$ \\
\hline $\mathrm{GH}$ pmol $\cdot \mathrm{L}^{-1}$ (baseline) & $144.2 \pm 69.8$ & $41.9 \pm 32.6^{*}$ \\
\hline IGF-1 $\left(\mu \mathrm{g} \cdot \mathrm{L}^{-1}\right)$ & $293 \pm 88$ & $278.4 \pm 43$ \\
\hline IGFBP-3 $\left(\mu g \cdot L^{-1}\right)$ & $3.9 \pm 0.4$ & $4.1 \pm 0.5$ \\
\hline IGFBP-1 $\left(\mu \mathrm{g} \cdot \mathrm{ml}^{-1}\right)$ & $58.4 \pm 21.2$ & $60.8 \pm 22.6$ \\
\hline
\end{tabular}

Note. Data are expressed as mean $\pm S D$. Basal hormone values are for eumenorrheic females from a previous study (Waters, 2001) who were matched for age and current training regiment with the amenorrheic females in this study. $\mathrm{P} 4=$ progesterone, $\mathrm{GH}=$ growth hormone, IGF-1 = insulin-like growth factor-1, IGFBP-3 = insulin-like growth factor binding protein-3, IGFBP-1 = insulin-like growth factor binding protein-1. *Significant difference by Student's $t$ test between groups, $p<.05$.

Data from five eumenorrheic athletes who were recruited in a previous study (Waters et al., 2001), and who matched the amenorrheic athletes for age and current exercise regimen were utilized for baseline (pre-treatment) hormonal and demographic comparisons only. For these subjects, basal progesterone samples were collected during the midluteal phase of the menstrual cycle. All other hormones were collected in the early follicular phase of the menstrual cycle.

\section{ADMINISTRATION OF THE TRANSDERMAL PLACEBO AND ESTROGEN PATCH}

Subjects underwent three treatments in a single-blinded, nonrandomized treatment order: a) 72-hour placebo control (t1); b) 72-hour estradiol transdermal replacement ( 2 x 0.05 mg patches, Estraderm ${ }^{\circledR}$ Ciba-Geigy), (t2) and; c) an additional $72-$ hour estradiol transdermal replacement $\left(2 \times 0.05\right.$ mg patches, Estraderm ${ }^{\circledR}$ CibaGeigy), ( $\mathrm{t} 3$ ). To limit the possibility of a carry-over effect on circulating blood estradiol concentrations, the placebo trial always preceded the estrogen replacement trials.

Non-medicated patches were placed on the skin of the upper buttock region for a period of $72 \mathrm{~h}$ after which the initial endurance exercise trial proceeded (t 1$)$. 
$\mathbf{A}$

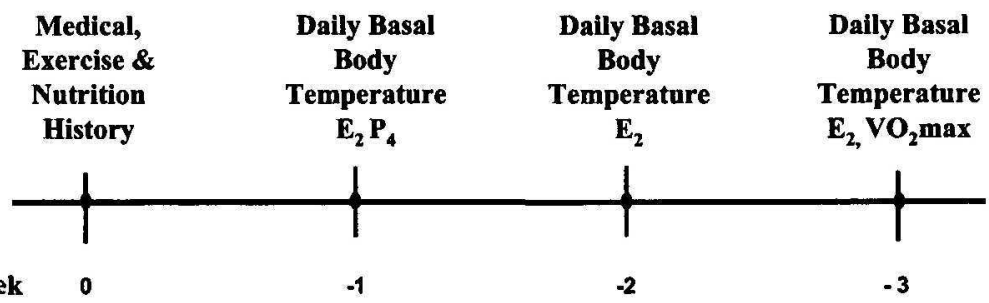

B

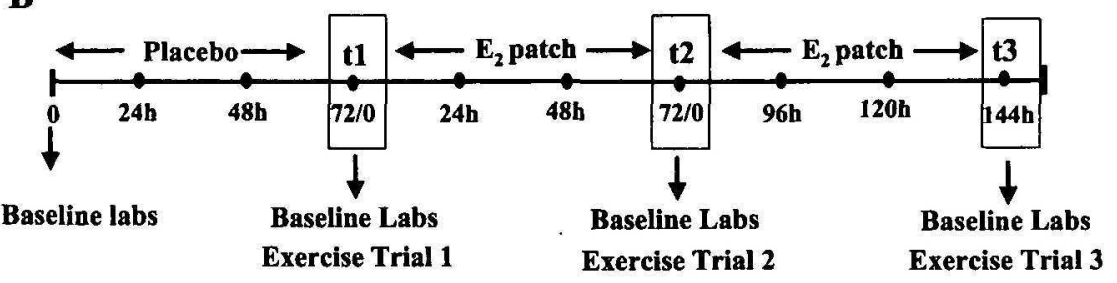

Figure 1. Pre-treatment screening and baseline evaluation (A), and placebo and transdermal estradiol trials timeline (B) for the seven subjects.

Following the initial exercise trial, the placebo transdermal patches were removed and replaced with an identical looking pair of estradiol (E2) medicated patches. The estradiol transdermal patches provided a total dose of $0.1 \mathrm{mg}$ estradiol every 24 hours to elicit a mid-late follicular stage estradiol concentration (74.9-149.9 pg $\left.\cdot \mathrm{ml}^{-1}\right)$. After wearing the medicated patches for $72 \mathrm{~h}$, the endurance exercise was repeated $(\mathrm{t} 2)$. Upon completion of the exercise trial, the medicated patches were removed and replaced with a pair of new medicated patches. The subjects performed a third exercise trial after an additional $72 \mathrm{~h}$ of transdermal E2 replacement (t3). Details of the study design are presented in Figure 1.

\section{SUB-MAXIMAL ENDURANCE EXERCISE TRIAL}

Prior to the placement of the control placebo patch, each subject underwent a modified incremental exercise test on a treadmill to measure $\mathrm{VO}_{2}$ max. Expired air samples were collected at 20 s intervals during each trial, and analyzed (Jaeger ${ }^{\mathrm{TM}}$ Ergo-oxyscreen Cardiopulmonary System). Criterion for $\mathrm{VO}_{2} \max$ was a plateau in the $\mathrm{VO}_{2}$ and Respiratory Exchange Ratio (RER) greater than 1.1. Heart rate was determined by electrocardiography during the last 10 seconds of each work stage. Prior to each of the three exercise trials, the subjects were hospitalized overnight to control for activity and food intake. Subjects consumed identical pre-testing meal for each trial and dietary recall data were analyzed during the $72 \mathrm{~h}$ prior to each exercise trial. From $2100-0600 \mathrm{~h}$ the subjects fasted but were allowed caffeine-free beverages. At $0600 \mathrm{~h}$ following the overnight hospital admission, a catheter was placed in the antecubital vein and kept patent by a $10 \mathrm{cc} \cdot \mathrm{h}^{-1}$ continuous 
drip of $0.45 \%$ half-normal saline. Fasting baseline blood samples were obtained at the GCRC prior to the subject being transported to the Center for Exercise and Applied Human Physiology (CEAHP). The subjects were transported to the CEAHP and subsequently rested in a supine position for 2 hours. The exercise trial began at $0800 \mathrm{~h}$ and consisted of 90 minutes treadmill running at $65 \% \mathrm{VO}_{2}$ max. Sample collection times were as follows: serum GH: $0,15,30,45,60,75$, and $90 \mathrm{~min}$. Serum estradiol and serum IGFBP-1: 0, 45, and $90 \mathrm{~min}$. Basal serum GH, IGF-1, IGFBP-3, estradiol, insulin, glucose and free fatty acid blood samples were obtained at $t 1, t 2$, and $t 3$ prior to the exercise tests.

\section{MEASUREMENTS}

Basal blood samples for GH, IGF-1, IGFBP-1, IGFBP-3, insulin, free fatty acids and glucose were obtained at the GCRC in the morning following a 12-hour fast, and prior to transport to the CEAHP laboratory. Blood sampling during the submaximal exercise trials occurred at intervals as depicted in Figure 1. Due to the reportedly slow rates of change in IGFBP-3 and IGF-1 concentrations (De Leo et al., 1993), these hormones were sampled at baseline only in each trial.

Upon obtaining each blood sample, whole blood samples for GH, IGF-1, IGFBP-1, IGFBP-3, estradiol, free fatty acids, insulin and glucose were centrifuged at $3000 \mathrm{RPM}$ at $4{ }^{\circ} \mathrm{C}$. Serum was then drawn off and frozen at $-70^{\circ} \mathrm{C}$ for subsequent analysis.

Serum GH and estradiol samples were analyzed using a double-antibody method (Diagnostic Products Corp., Los Angeles, CA). Intra- and inter- assay variability for $\mathrm{GH}$ was $2.8 \%$ and $5.3 \%$ respectively with $0.2 \mathrm{ng} \cdot \mathrm{ml}^{-1}$ sensitivity. Intraand inter- assay variability for estradiol was $7.0 \%$ and $8.1 \%$ respectively with 7.9 $\mathrm{pg} \cdot \mathrm{ml}^{-1}$ sensitivity. Serum IGF-1 was analyzed using the RIA acid-ETOH extraction method (Nichols Institute Diagnostics, San Juan Capistrano, CA). Sensitivity was $0.06 \mu \mathrm{g} \cdot \mathrm{L}^{-1}$. Intra- and inter-assay variability for IGF-1 was $2.4 \%$ and $5.2 \%$ respectively. Serum IGFBP-3 was analyzed using RIA (Nichols Institute Diagnostics, San Juan Capistrano, CA). Sensitivity was $0.06 \mu \mathrm{g} \cdot \mathrm{ml}^{-1}$ with intra- and interassay variability of $3.8 \%$ and $6.3 \%$, respectively. Serum IGFBP-1 was analyzed using IRMA (Diagnostic Systems Laboratories. Webster, Texas). Sensitivity was $0.33 \mu \mathrm{g} \cdot \mathrm{L}^{-1}$ with intra and inter-assay variability of $6.0 \%$ and $4.6 \%$, respectively. Glucose was analyzed using enzymatic spectrophotometric methods (Beckman liquid-stat run on Roche Cobas Bio). Insulin was assayed using double antibody RIA without extraction (Diagnostic Products Corp., Los Angeles CA).

\section{STATISTICS}

Baseline and peak concentrations, area under the curve for exercise serum $\mathrm{GH}$, estradiol, and IGFBP-1 were computed for each exercise trial and analyzed among the three trials using repeated measures (RM) ANOVA. If the overall RM ANOVA gave a significant result, then changes in baseline insulin, glucose, free fatty acids, serum IGF-1, serum IGFBP-3 were analyzed using paired Student's t-test as posthoc tests to the RM ANOVA. Pearson correlation coefficient was utilized for correlation analysis. Significance was set at $p<.05$ and all analyses were performed using Statistical Analysis System (SAS Institute, Carry, NC/STAT, 1990). 


\section{Results}

\section{SUBJECTS}

The subjects' physical and demographic characteristics are presented in Table 1. Compared to previous data from five eumenorrheic controls, serum estradiol and progesterone levels were significantly lower in the amenorrheic subjects, and resting $\mathrm{GH}$ was significantly increased (both, $p<.05$ ). Baseline serum IGF-1 and serum binding proteins were not significantly different between the amenorrheic subjects and the data from the eumenorrheic controls. These hormones were also within normal ranges reported for these assays for both the amenorrheic subjects and eumenorrheic control data.

\section{ESTRADIOL}

Baseline estradiol concentrations were significantly higher at $\mathrm{t} 2$ and $\mathrm{t} 3$ compared to $\mathrm{t} 1$ ( $\left.\mathrm{t} 1: 128.5 \pm 16.9, \mathrm{t} 2: 255.1 \pm 27.9 ; \mathrm{t} 3: 268.3 \pm 43.7 \mathrm{pmol} \cdot \mathrm{L}^{-1}, p=0.01\right)$. There were no significant differences in baseline estradiol concentrations between the $t 2$ and $\mathrm{t} 3$.

Exercise estradiol concentrations at 45 and 90 minutes of exercise were significantly increased from baseline $(p=0.02)$ with the highest estradiol concentration achieved at 90 minutes during the $\mathrm{t} 3$ trial (Figure 2).

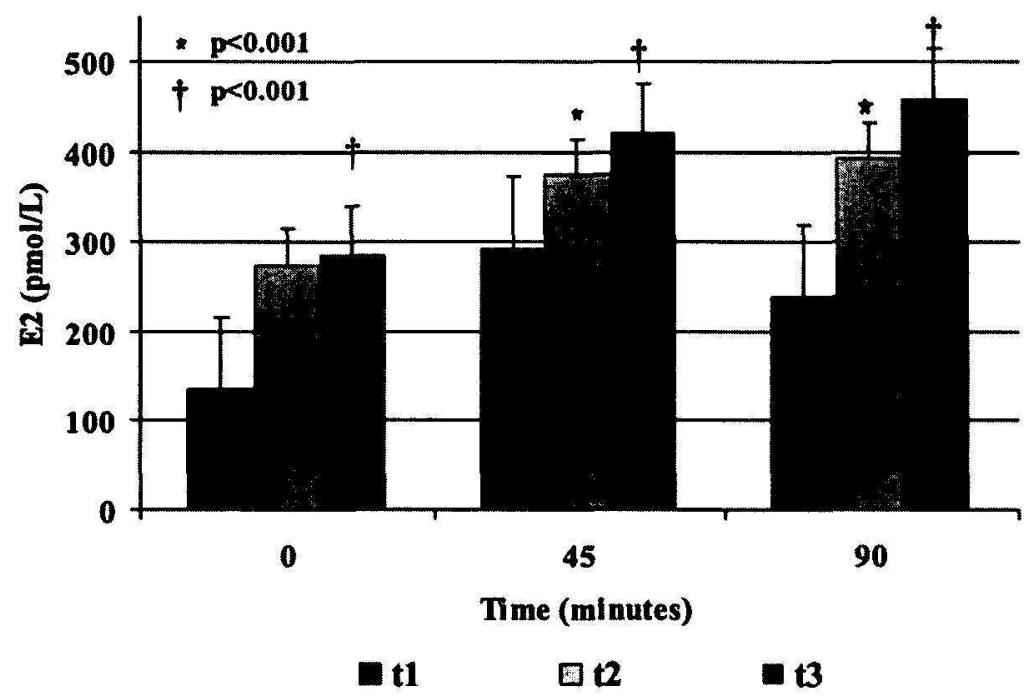

Figure 2. Estradiol response following 72 and 144 hours of transdermal estradiol supplementation and during 90 minutes exercise at $65 \% \mathrm{VO}_{2} \max$. Baseline estradiol significantly increased in response to transdermal estradiol supplementation and significantly increased in response to exercise. There were no differences at any time point between the $\mathrm{t} 2$ and $\mathrm{t} 3$ trials. $\mathrm{t} 1=$ placebo control trial, $\mathrm{t} 2=72$ hours estradiol, $\mathrm{t} 3=144$ hours estradiol. ${ }^{*} p<.01 \mathrm{t} 1$ vs $\mathrm{t} 2, \dagger=p<.01 \mathrm{t} 1$ vs $\mathrm{t} 3$. Data expressed as means $\pm \mathrm{SEM}$. 


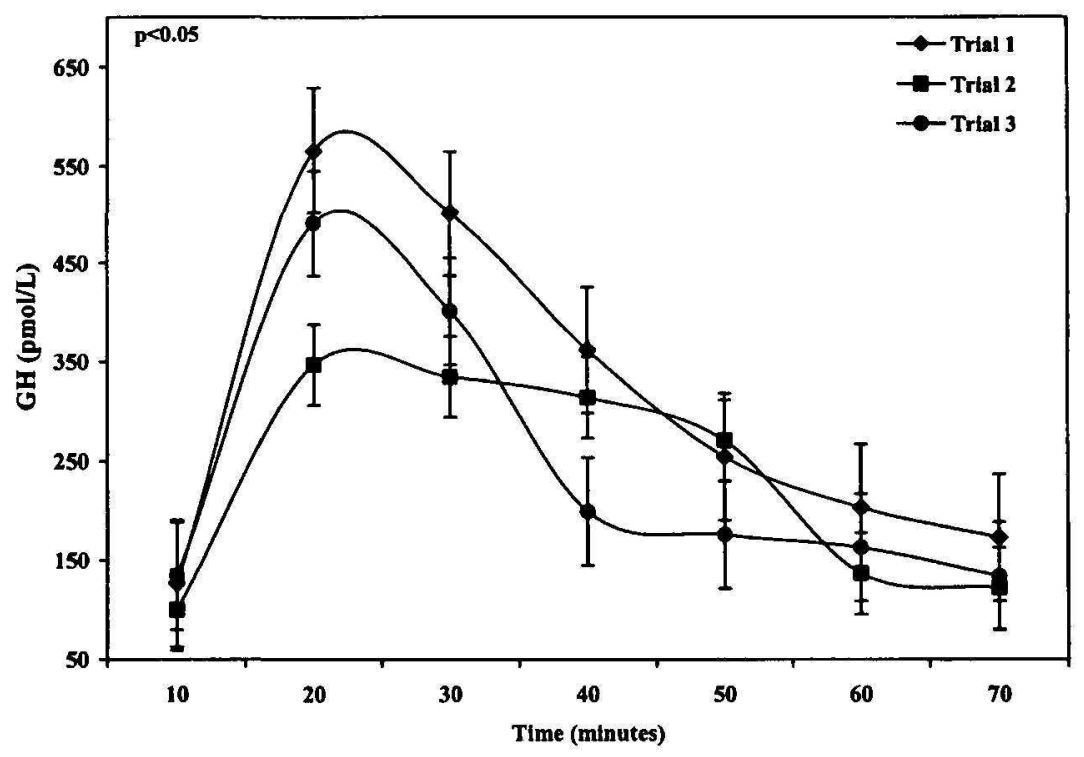

Figure 3. Growth hormone response to 90 minutes of exercise at $65 \% \mathrm{VO}_{2}$ max, following 72 and 144 hours of transdermal estradiol supplementation. Diamond (t1) $=72$ hours of placebo, Square $(t 2)=72$ hours estradiol supplementation, Triangle $(t 3)=144$ hours estradiol supplementation. Growth hormone significantly increased in response to exercise at 15 minutes $(p<.05)$. There were no significant differences between the trials.

\section{GROWTH HORMONE (GH)}

There were no significant differences between the $\mathrm{t} 1, \mathrm{t} 2$ or $\mathrm{t} 3$ trials for baseline serum GH concentration, peak GH, or GH area under the curve (AUC).

Mean GH concentrations for all three-exercise trials, increased significantly from baseline $\left(120.9 \pm 69.8 \mathrm{pmol} \cdot \mathrm{L}^{-1}\right)$ to a peak at approximately 15 minutes $\left(562.7 \pm 227.9 \mathrm{pmol} \cdot \mathrm{L}^{-1}, p=0.03\right.$, Figure 3$)$. Although peak serum GH concentrations were not different between trials, the apparent "flattening" of the curve at 2 , was attributable to a delayed time to peak $\mathrm{GH}$ in two subjects during this trial. This delay to peak was not present in $\mathrm{t} 3$.

\section{IGF-1, IGFBP-3, AND IGFBP-1}

Baseline serum IGF-1 and IGFBP-1 were not significantly different between trials. Baseline serum IGFBP-3 concentrations modestly, but significantly, decreased at $\mathrm{t} 2\left(3.69 \pm 0.48\right.$ vs $3.36 \pm 0.39 \mu \mathrm{g} \cdot \mathrm{L}^{-1}, p=.05$, Figure 4$)$.

During exercise, serum IGFBP-1 significantly increased with the peak value attained at 90 minutes in all trials $(p=0.01)$. There was no significant difference in IGFBP -1 between trials. 


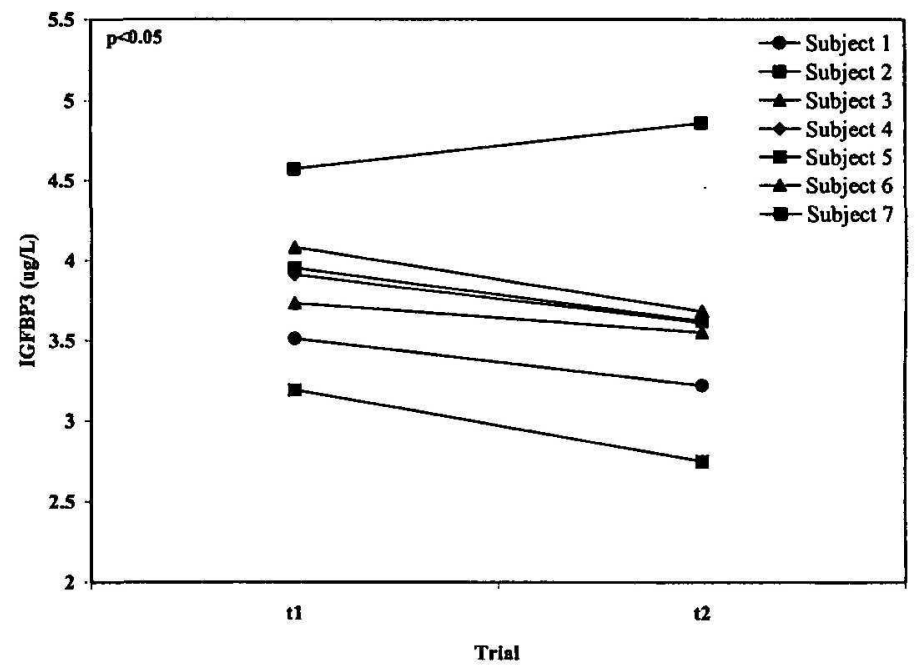

Figure 4. IGFBP3 response to $72(\mathrm{t} 2)$ hours of transdermal estradiol supplementation. IGFBP3 significantly decreased following 72 hours of estradiol supplementation $(p<$ .05). Data expressed as means \pm SEM.

Table 2 Baseline Serum Insulin, Glucose and Free Fatty Acid (FFA) Concentrations in Response to Transdermal Estradiol Supplementation $(N=6)$

Trial Insulin $\left(\mathrm{pmol} \cdot \mathrm{L}^{-1}\right) \quad$ Glucose $\left(\mathrm{mml} \cdot \mathrm{L}^{-1}\right)$ FFA $\left(\mathrm{mm} \cdot \mathrm{L}^{-1}\right)$

\begin{tabular}{llll}
\hline t1 & $28.13 \pm 0.04$ & $3.89 \pm 0.37$ & $0.28 \pm 0.16$ \\
t2 & $21.95 \pm 4.11$ & $3.76 \pm 0.28$ & $0.41 \pm 0.27^{*}$ \\
t3 & $24.11 \pm 6.02$ & $3.82 \pm 0.32$ & $0.40 \pm 0.27^{*}$ \\
\hline
\end{tabular}

Note. Variables are expressed as mean $\pm \mathrm{SE}$. $\mathrm{tl}=72$ hours placebo, $\mathrm{t} 2=72$ hours treatment with transdermal estradiol, $\mathrm{t} 3=144$ hours treatment with transdermal estradiol. ${ }^{*} p<.05$ comparison to $\mathrm{t} 1$.

\section{METABOLIC SUBSTRATES}

Baseline serum free fatty acids significantly increased from $t 1$, compared to $t 2$, and $\mathrm{t} 3$ (overall $p=0.03$ ). Baseline serum insulin and glucose concentrations were not significantly different between trials and were within the reported normal ranges for these assays (Table 2).

\section{PHYSIOLOGIC PARAMETERS}

There were no significant differences in heart rate, $\mathrm{VO}_{2}, \mathrm{RER}$ (Table 3), or dietary intake between the exercise trials. 
Table 3 Heart Rate, VO and RER During the Endurance Exercise Trials $(N=7)$

\begin{tabular}{lccc}
\hline Trial & Heart rate $(\mathrm{bpm})$ & $\mathrm{VO}_{2}\left(\mathrm{ml} \cdot \mathrm{kg}^{-1} \cdot \mathrm{min}^{-1}\right)$ & RER \\
\hline $\mathrm{t} 1$ & $152 \pm 15$ & $29.49 \pm 3.33$ & 0.92 \\
$\mathrm{t} 2$ & $148 \pm 13$ & $29.28 \pm 3.01$ & 0.91 \\
$\mathrm{t} 3$ & $150 \pm 16$ & $28.77 \pm 3.46$ & 0.90
\end{tabular}

Note. Variables are expressed as mean $\pm \mathrm{SD} . \mathrm{t} 1=72$ hours placebo, $\mathrm{t} 2=72$ hours treatment with transdermal estradiol, $\mathrm{t} 3=144$ hours treatment with transdermal estradiol. $\mathrm{bpm}=$ beats per minute, $R E R=$ respiratory exchange ratio. There were no significant differences between the trials for heart rate, $\mathrm{VO}_{2}$ or RER.

\section{Discussion}

In the present study, we examined the effects of short-term estradiol replacement on the GH/IGF-1 axis in a group of weight-stable young women with amenorrhea due to exercise. To our knowledge, the present report is the first study of transdermal estradiol effects on the GH/IGF-1 axis in this specific cohort of females with amenorrhea.

Three principal findings emerged from this study. First, administration of transdermal estradiol significantly increased baseline serum free fatty acid concentrations and modestly decreased serum IGFBP-3 levels. Second, transdermal estradiol replacement had no effect on baseline or exercise-stimulated serum GH concentrations.

Third, prior to estradiol supplementation, exercise significantly increased serum levels of GH, IGFBP-1, and estradiol, but transdermal estradiol did not change exercise- stimulated responses of these hormones.

\section{BASELINE HORMONES - PRE AND POST ESTRADIOL SUPPLEMENTATION}

In our investigation, administration of transdermal estrogen produced physiological concentrations of estradiol that influenced several biological endpoints. This included increased baseline levels of free fatty acids, and decreased serum levels of IGFBP-3 with no effect on baseline serum GH, IGFBP-1, insulin or glucose.

The estrogen-dependent increase in baseline FFA contrasts with previously reported estradiol effects in postmenopausal females, in whom transdermal estradiol was observed to decrease FFA levels (Bhathena et al., 1998; O'Sullivan et al., 1998).

However, there are two potential explanations for this result. It has been reported that the basal rates of triglyceride breakdown, fatty acid release into plasma, fatty acid oxidation, and triglyceride-fatty acid substrate cycling are two-to fourfold higher in endurance trained male athletes compared to untrained males (Romijn et al., 1993). The authors postulated that the increase in lipid kinetics was due to an 
increased rate of triglyceride-fatty acid substrate cycling in the resting state, and also increased sensitivity of adipose tissue lipolysis to hormonal control. (Romijn et al.,1993). They excluded inadequate calorie or carbohydrate intake, and/or depleted glycogen stores as potential factors in their investigation. In the present study, we also controlled for differences in dietary intake utilizing a 72 hour dietary recall prior to each exercise trial, and standardized meals during the overnight hospital admissions. We found no significant differences in total calories or caloric content and are confident that dietary factors did not influence our results. However, the proposed mechanism of increased adipose tissue lipolysis sensitivity to hormonal control is considered below (Romijn et al., 1993).

In adipose tissue, 17-beta-estradiol has a direct effect on lipoprotein lipase and hormone-sensitive lipase; whereas in the liver it regulates the rate of synthesis of apolipoproteins (Szafran and Smielak-Koromkel, 1998). Lipoprotein lipase is involved with clearing triglyceride-rich chylomicrons and very-low-density lipoprotein particles from the blood stream, providing free fatty acids to adipose tissue and skeletal muscle. Hormone sensitive lipase mediates the lipolysis of triacylglycerol resulting in the release of non-esterified fatty acids and glycerol (Slavin et al., 1994). The hormone 17-beta-estradiol also has indirect actions on adipose tissue by stimulating the release of catecholamines, growth hormone, and glucagon resulting in increased hormone sensitive lipase activity (Szafran and Smielak-Koromkel, 1998). Although we did not report any increase in basal or exercise growth hormone concentrations in this study, we previously reported increases in resting epinephrine, and norepinephrine concentrations during transdermal estradiol supplementation in amenorrheic athletes (Ruby et al., 1997). Due to thier small sample size and intra-subject variability in epinephrine and norepinephrine, these hormonal measures failed to reach statistical significance (Epinephrine: $0.17 \pm 0.09$ vs $0.24 \pm 0.13 \mathrm{nmol} \cdot \mathrm{L}$ and Norepinephrine: $3.01 \pm 1.2$ vs. $3.2 \pm 1.1 \mathrm{nmol} \cdot \mathrm{L}$, respectively). It is noteworthy however, that norepinephrine concentrations, in particular, were greater than the reported normal range of $0.7-$ $2.4 \mathrm{nmol}$ - L. Norepinephrine interacts with beta-adrenergic receptors activating adenylyl cylase, which forms cAMP. The cAMP activates protein kinase $A$, which activates hormone sensitive lipase (Bray, 1992). Thus, it is conceivable that the increase in our resting (fasting) FFA during transdermal 17-beta-estradiol therapy may have been secondary to indirect catecholamine effects of 17-beta-estradiol on lipid metabolism and endurance training effects on adipose tissue sensitivity to hormones. These relationships, and also the potential for a synergistic effect between 17-beta-estradiol and endurance training effects on lipid metabolism in amenorrheic female athletes warrant further investigation.

\section{SERUM ESTRADIOL, GH AND IGFBP-1 DURING EXERCISE PRE AND POST ESTRADIOL SUPPLEMENTATION}

Estradiol. The increase in estradiol levels observed during all exercise trials could be related to several factors including increased ovarian production of estradiol, increased cutaneous blood flow leading to augmented absorption from the estradiol patch, or delayed clearance of estradiol. We favor the concept of delayed clearance, because if one looks at Figure 2, it is apparent that the estradiol delta in 11 compared to $\mathrm{t} 2$ and $\mathrm{t} 3$ are almost identical. Furthermore, a previous study also 
demonstrated that the exercise-induced shunting of blood flow away from the liver leads to an increase in the half-life and serum level of estradiol, thus favoring the premise of decreased clearance (Chen and Brzyski, 1999).

$\boldsymbol{G H}$. Exercise is a stimulus for $\mathrm{GH}$ secretion, and therefore the rise in GH concentrations associated with exercise as shown in Figure 3 were expected. The apparent blunting of the serum GH response during exercise at $\mathbf{t} 2$ was related to a delay in the GH peaks in two subjects. A similar effect of transdermal estradiol on the timing of the GH peak in post-menopausal females has also been reported (Cano et al., 1999), although the lack of this effect at $t 3$ in our study indicates that this was most likely an anomaly of that trial.

Estradiol administration had no effect on baseline or peak exercise-stimulated GH concentrations. The lack of an estrogen effect on basal or stimulated GH levels in spite of significantly increased baseline E2 levels in amenorrheic athletes may be related to either the duration of estrogen replacement or to the estradiol dose (Bellantoni et al., 1996; Friend et al., 1996; Goodman-Gruen and BarrettConner, 1996). Previous studies in postmenopausal women and in women with hypothalamic amenorrhea associated with weight- loss, have reported that transdermal estradiol administration increased nocturnal, integrated GH AUC, and spontaneous episodic GH release (Friend et al., 1996; Genazzani et al., 1993, 1998). Conversely, transdermal estradiol in postmenopausal females has been reported to not alter nocturnal GH secretion, or morning IGF-1, but decrease IGFBP-3 (Bellantoni et al., 1996). These disparate findings raise the question of underlying physiological differences in the amenorrhea of menopause, hypothalamic amenorrhea due to weight-loss, and amenorrhea secondary to exercise in weight-stable athletes.

IGF-1. Our serum IGF-1 findings are in agreement with a report of no change in IGF-1 during short-term estradiol supplementation in postmenopausal females (Bellantoni et al., 1996), and are in contrast to other reports of increased IGF-1 with transdermal estradiol (Genazzani et al., 1998; Weissberger et al., 1991). The report of increased IGF-1 with transdermal estradiol included both hypogonadotropic and normogonadotrophic weightloss-associated amenorrheics and concluded that the hormonal abnormalities in amenorrhea related to weight loss were only partially dependent on the hypoestrogenic condition. Others have also postulated that the inability to fully restore the GH/IGF-1 axis with estradiol supplementation may be dependent on an intact ovarian-pituitary feedback system (Weissberger et al., 1991). However, in our previous study, normal-weight amenorrheic athletes demonstrated elevated GH concentrations between pulses, and disrupted nocturnal serum GH secretion, but no differences in serum IGF-1 compared to closely matched eumenorrheic athletes, both of whom presumably had an intact ovarianpituitary feedback (Waters et al., 2001) . Furthermore, during exercise the normal relationship between IGF-1 and GH was completely reversed in the amenorrheic females. This uncoupling of E2 regulation of the GH/TGF-1 axis has been reported in aging female primates (Wilson, 1998). If the amenorrheic females in our current investigation had disrupted nocturnal GH secretory kinetics as reported by ourselves and other investigators (Laughlin et al., 1998; Waters et al., 2001; Yen and Laughlin, 1996), this might account for an uncoupling between the normal relationship of E2 and the GH/IGF-1 axis. 
IGFBP-1. The mechanism for exercise-induced increase in IGFBP-1 has been reported in several studies and is likely due to decreases in insulin during prolonged exercise (Cano et al., 1999; Jenkins et al., 1993; Lee et al., 1993). In our study, exercise significantly increased IGFBP-1 levels, but there was no difference in exercise-stimulated IGFBP-1 during transdermal estradiol supplementation. Additionally, neither baseline nor exercise-stimulated IGFBP-1 was affected by increasing estradiol concentrations. This lack of an IGFBP-1 response to estradiol is somewhat surprising, since sex steroids have been reported to negatively regulate IGFBP-1 (Cano et al., 1999; Prange-Hansen and Weeke, 1974), and transdermal estradiol apparently decreases IGFBP-1 (Cano et al., 1999; Jenkins et al., 1993; Lee et al., 1993). However, baseline IGFBP-1 concentrations in our amenorrheic athletes in this investigation were not elevated as reported by others (Jenkins et al., 1993), nor did we find a relationship between menstrual status and IGFBP-1 in our previous study of eumenorrheic and amenorrheic athletes with comparable estradiol concentrations (Waters et al., 2001). Therefore, the unresponsiveness of IGFBP1 to increasing serum estradiol levels may be due to the short duration of therapy or final serum concentrations of estradiol attained.

\section{Limitations and Conclusion}

The present study focuses on a unique cohort of women with athletic amenorrhea from which women athletes with severe eating disorders were excluded. The selection of this group of females with a specific etiology of amenorrhea is important for excluding the potential contributions of severe nutritional deficiencies and metabolic alterations on the activity of the GH/IGF-1axis. However, several limitations to our findings should be discussed.

Although the differences we report in IGBP-3 appear small, another investigation also reported a similar small decrease in postmenopausal females (Bellantoni et al., 1996). We conducted a post-hoc power analysis of our main hypothesis that IGFBP-3 will decrease with transdermal estrogen therapy, and used the observed standard deviation for the ( $t 2$ vs $t 1$ ) differences in IGFBP-3 level of $0.25 \mu \mathrm{g} / \mathrm{L}$. Using this, our sample size of $n=7$ was adequate to detect a $0.32 \mu \mathrm{g} / \mathrm{L}$ difference with $80 \%$ power and $\alpha=0.05$. However, the physiological relevance of this finding is unclear, as the normal range for IGFBP-3 in adult females is $2.0-4.9 \mu \mathrm{g}$. $\mathrm{L}^{-1}$, and the $6 \%$ change we reported, was still in the normal range. Thus, the physiological consequence of this finding is most likely insignificant.

We also recognize that this study was not well powered for Type-II errors. A post-hoc power analysis for changes in IGF-1 based on the observed standard deviation of these changes ( $\mathrm{t} 1 \mathrm{vs} \mathrm{t} 2$ ) of $23.2 \mu \mathrm{g} / \mathrm{L}$ revealed that our sample size of $n$ $=7$ was adequate to detect a $30 \mu \mathrm{g} / \mathrm{L}$ difference with $80 \%$ power and $\alpha=0.05$. This change is approximately a $10 \%$ difference from baseline IGF-1 levels. Note that the within-subject standard deviation of 23.2 is much less than the betweensubject standard deviation of 88 , which indicates the difficulty in intra-subject variability in hormonal concentrations.

Finally, it will be important to assess whether the observed discrepancies we report from this study are due to differences in the dose or duration of transdermal estradiol replacement or reflect important biological differences in the GH/IGFlaxis in the etiology of athletic amenorrhea. Although the transdermal estradiol 
patch brought estradiol levels into a mid-follicular range, the short duration of the therapy limits the interpretation of our results. Further studies are needed utilizing a 6-12 week course of therapy, varying doses, and with the inclusion of eumenorrheic controls to make this cohort study comparable to amenorrhea of different etiologies.

\section{Acknowledgments}

We would like to thank the following people for their support: Mark Burge, M.D. for inpatient hospital admissions, Christine Mermier and Lisa Stolarczyk of the Center for Exercise and Human Physiology, the 5-East nursing staff at the University Hospital/ Clinical Research Center and the Clinical Research Center laboratory technicians, and Jennifer Harrington and Elizabeth Duran-Valdez for their editorial contributions. The estradiol patches (Estraderm ${ }^{\otimes}$ ) were generously donated by Ciba-Geigy. This study was supported by NCRR-GCRC Grant \#MO1 RR00997.

\section{References}

Bellantoni, M.F., Vittone, J., and Campfield, A.T. (1996). Effects of oral versus transdermal estrogen on the growth hormone/insulin-like growth factor I axis in younger and older menopausal women: A clinical research center study. J. Clin. Endocrinol. Metab. 81: 2848-2853.

Bhathena, R.K., Anklesaria, B.S., Ganatra, A.M., and Pinto, R. (1998). The influence of transdermal estradiol replacement therapy and medroxyprogesterone acetate on serum lipids and lipoproteins. Br. J. Clin. Pharmacol. 45: 170-172.

Bray,G.A. (1992). Peptides affect the intake of specific nutrients and the sympathetic nervous system. Am. J. Clin. Nutr. 55: 265 S.

Cano, A., Castelo-Branco, C., and Tarin, J. (1999). Effect of menopause and different combined estradiol-progestin regimens on basal and growth hormone-releasing hormonestimulated serum growth hormone, insulin-like growth factor-1, insulin-like growth factor binding protein (IGFBP)-1, and IGFBP-3 levels. Fertil. Steril. 71: 261-267.

Chen, E.C., and Brzyski, R.G. (1999). Exercise and reproductive function. Fertil. Steril. 71: $1-6$.

De Cree, C., (1998). Sex steroid metabolism and menstrual irregularities in the exercising female. Sports Med. 25: 369-405.

De Leo, V., Lanzetta, D., D'Antona, D., and Danero, S. (1993). Growth hormone secretion in premenopausal women before and after ovariectomy: effect of hormone replacement therapy. Fertil. Steril. 60: 268-271.

Friend, K.E., Hartman, M.L., Pezzoli, S.S., Clasey, J.L., and Thorner, M.O. (1996). Both oral and transdermal estrogen increase growth hormone release in postmenopausal women-A clinical research study. J. Clin. Endocrinol. Metab. 81: 2250-2256.

Garner, R., Olmstead, H., Bohr, L., and Garfinkel, G. (1982). The eating attitudes test: Psychometric features and clinical correlates. Psych. Med. 12: 871-78.

Genazzani, A.D., Gamba, O., and Petraglia, F. (1998). Estrogen replacement therapy modulates spontaneous GH secretion but does not affect GH-RH-induced GH response and low T3 syndrome in women with hypothalamic amenorrhea associated to weight loss. J. Endocrinol. Invest. 21: 353-357.

Genazzani, A.D., Petraglia, F., and Volpogni, C. (1993). Modulatory role of estrogens and progestins on growth hormone episodic release in women with hypothalamic amenorrhea. Fertil. Steril. 60: 465-70. 
Goodman-Gruen, D., and Barrett-Conner, E. (1996). Effect of replacement estrogen on insulin-like growth factor-I in postmenopausal women: Rancho Bernardo Study. J. Clin. Endocrinol. Metab. 81: 4268-4271.

Jenkins, P.J., Ibanez-Santos, X., and Holly, J. (1993). IGFBP1: A metabolic signal associated with exercise induced amenorrhea. Neuroendocrinology 57: 600-604.

Koistinen, H., Koistinen, R., Selenius, L., Ylikorkala, O., and Seppala, M. (1996). Effect of marathon run on serum IGF-1 and IGF-binding protein 1 and 3 levels. J. Appl. Physiol. 80(3): 760-764.

Laughlin, G.A., Dominguez, C.E., and Yen, S.S. (1998). Nutritional and endocrine metabolic aberration in women with functional hypothalamic amenorrhea. J. Clin. Endocrinol. Metab. 83: 25-32.

Lee, P.D., Conover, C.A., and Powell, D.R. (1993). Regulation and function of insulin-like growth factor-binding protein1. Proc. Soc. Exp. Biol. Med. 204: 4-29.

Loucks, A., and Horvath, S. (1985). Athletic amenorrhea: A review. Med. Sci. Sports Exerc. 17: $56-72$.

O'Sullivan, A.J., Crampton, L., Freund, J., and Ho, K.K. (1998). The route of estrogen replacement therapy confer divergent effects on substrate oxidation and body composition in postmenopausal women. J. Clin. Invest. 102: 1035-40.

Prange-Hansen, A.A., and Weeke, J. (1974). Fasting serum growth hormone levels and growth hormone responses to exercise during normal menstrual cycles and cycles of oral contraceptives. Scand. J. Clinic. Lab. Invest. 34: 199-205.

Romijn, J.A., Klein, S., Coyle, E.F., Sidossis, L.S., and Wolfe, R.R. (1993). Strenuous endurance training increases lipolysis and triglyceride-fatty acid cycling at rest. J. Appl. Physio. 75(1): 108-113.

Ruby, B.C., Robergs, R.A., Waters, D.L., Burge, M., Mermier, C., and Stolarcyzk, L. (1997). Effects of estradiol on substrate turnover during exercise in amenorrheic females. Med. Sci. Sports Exerc. 29: 1160-1169.

Slavin, B.G., Ong, J.M., and Kern, P.A. (1994). Hormonal regulation of hormone sensitive lipase activity and mRNA levels in isolated rat adipocytes. J. Lipid. Res. 35(9): 1535-41.

Szafran, H., and Smielak-Korombel, W. (1998). The role of estrogens in hormonal regulation of lipid metabolism in women. Przegl. Lek. 55(5): 266-70.

Waters, D.L., Qualls, C.R., Dorin, R., Veldhuis, J.D., and Baumgartner, R.N. (2001). Increased pulsatility, process irregularity, and nocturnal trough concentrations of growth hormone in amenorrheic compared to eumenorrheic athletes. J. Clin. Endocrinol. Metab. 86(3): 1013-1019.

Weissberger, A., Ho, K., and Lazarus, L. (1991). Contrasting effects of oral and transdermal routes of estrogen replacement therapy on 24-hour growth hormone (GH) secretion, insulin-like growth factor-I, and GH binding protein in postmenopausal women. J. Clin. Endocrinol. Metab. 72: 374-81.

Wilson, M.E. (1998). Regulation of the growth hormone-insulin-like growth factor I axis in developing and adult monkeys is affected by estradiol replacement and supplementation with IGF1. J. Clin. Endocrinol. Metab. 83: 2018-28.

Yen, S.S.C. (1993). Female hypogonadotropic hypogonadism. Endo. Metab. Clinic North Amer. 22: 29-58.

Received October 18, 2000; accepted in final form February 19, 2002. 